\title{
The Relationship between Second-to-Fourth Digit Ratios, Attention-Deficit/Hyperactivity Disorder Symptoms, Aggression, and Intelligence Levels in Boys with Attention-Deficit/Hyperactivity Disorder
}

\author{
Ümit Işık ${ }^{1 凶}$, Faruk Kılıç ${ }^{2}$, Evrim Aktepe ${ }^{1}$, and Bilal Tanrıtanır ${ }^{3}$ \\ ${ }^{1}$ Department of Child and Adolescent Psychiatry, Suleyman Demirel University Faculty of Medicine, Isparta, Turkey \\ ${ }^{2}$ Department of Psychiatry, Suleyman Demirel University Faculty of Medicine, Isparta, Turkey \\ ${ }^{3}$ Department of Psychiatry, Bucak State Hospital, Burdur, Turkey
}

\begin{abstract}
Objective Observations of sex differences have led some scientists to doubt whether the neuroendocrine system is involved in attentiondeficit/hyperactivity disorder (ADHD) etiology. One of the interesting study subjects in this context is prenatal steroid hormone exposure. The aim of the present study was to replicate and extend previous work by addressing two research questions: 1) Are second-tofourth digit (2D:4D) ratios lower in ADHD than in controls? 2) Is there a correlation between 2D:4D ratios and symptoms of $\mathrm{ADHD}$, aggression and intelligence scores in boys with ADHD?

Methods The study included 100 treatment-naive male children diagnosed with ADHD and 55 healthy male children. We measured the ratios of 2D:4D and administered a Wechsler Intelligence Scale for Children-Revised to assess IQ scores, as well as behavioral rating scales, in children with ADHD and comparison individuals.

Results We observed lower 2D:4D ratios in the right hand in ADHD in comparison to the control group. The left-hand ratios of 2D:4D, however, did not differ between $\mathrm{ADHD}$ and control groups. There were negative correlations between the left-hand 2D:4D ratios and the hyperactivity scores. However, no significant correlation was detected between right-hand 2D:4D ratios and the psychological questionnaire scores.
\end{abstract}

Conclusion These results provide further evidence that fetal androgen exposure may contribute to the pathophysiology of ADHD, at least in boys. Psychiatry Investig 2020;17(6):596-602

Key Words Aggression, Attention-deficit/hyperactivity disorder, Intelligence, Prenatal steroid hormone exposure, Second-to-fourth digit ratios.

\section{INTRODUCTION}

Attention-deficit/hyperactivity disorder (ADHD) is a neurodevelopmental disorder that begins in childhood and adversely affects functionality in many ways. In a study conducted in Turkey in recent years, the authors investigated the prevalence of childhood psychopathology and found that the most

Received: January 5, 2020 Revised: March 18, 2020

Accepted: April 15, 2020

$\triangle$ Correspondence: Ümit Ișı, MD

Department of Child and Adolescent Psychiatry, Suleyman Demirel University Faculty of Medicine, Isparta 32260, Turkey

Tel: +90 24621193 46, E-mail: crsumt@gmail.com

(c) This is an Open Access article distributed under the terms of the Creative Commons Attribution Non-Commercial License (https://creativecommons.org/licenses/by$\mathrm{nc} / 4.0$ ) which permits unrestricted non-commercial use, distribution, and reproduction in any medium, provided the original work is properly cited. common psychiatric disorder was $\mathrm{ADHD}$ with a prevalence of $12.4 \% .{ }^{1}$ The prevalence of the disorder in boys is higher than in girls, and the ratio between boys and girls ranges from 2:1 to $10: 1$. $^{2,3}$ Although several possible biomarkers for ADHD have been identified, ${ }^{4}$ the precise etiology of ADHD is not established. ${ }^{5,6}$ Observations of sex differences have led some scientists to doubt whether the neuroendocrine system is involved in ADHD etiology. ${ }^{7-9}$ One of the interesting study subjects in this context is prenatal steroid hormone exposure. ${ }^{10-15}$

Unfortunately, prenatal steroid hormone measurement is invasive and costly. Recent evidence has shown that the ratio of index finger (2D) length to the ring finger (4D), expressed as second-to-fourth digit (2D:4D), is constant throughout a lifetime and is inversely associated with prenatal testosterone exposure, is considered as a marker for the intrauterine level of 
testosterone. ${ }^{16-18}$ Therefore, several investigators have used the ratio of 2D:4D to examine the relationship between fetal testosterone exposure and neurodevelopmental disorders like $\mathrm{ADHD}$ as a noninvasive indicator of fetal testosterone exposure. While some of these studies were performed in the unselected population samples, ${ }^{19-21}$ some of them were performed with clinically diagnosed ADHD. ${ }^{12-15,22,23}$ In studies conducted with community samples, all studies have shown that more masculine ratios have been associated with increased symptoms; ${ }^{19-21}$ some research, however, found this relationship only in girls, ${ }^{19,20}$ while other studies found these relations only in boys. ${ }^{21}$ Among patients with clinically diagnosed ADHD, only a few studies investigated the 2D:4D ratios. In one of these studies, the ratios of 2D:4D in male ADHD patients are lower than in male anxiety disorder patients. ${ }^{22}$ Similarly, in another study, the 2D:4D ratio in children with ADHD was found to be lower than controls, but this difference could not be seen in the female sample. ${ }^{23}$ Martel et al., ${ }^{13}$ showed that the righthand ratio of $2 \mathrm{D}: 4 \mathrm{D}$ distinguishes between $\mathrm{ADHD}$ and controls in males and that more masculine ratios in males associated with inattentive and hyperactive-impulsive symptoms, reported by parents and teachers. In a study conducted in Turkey, 40 boys with ADHD were compared with 40 healthy controls. The right-hand 2D:4D ratios in the ADHD sample were found to be significantly lower compared to the controls and were found to be associated with high aggression scores in this study. ${ }^{14}$ Also, studies are reporting that 2D:4D ratios did not differ between ADHD and control groups. ${ }^{15}$

When the results of the studies are evaluated, they have shown that people with a lower, more male-typical, 2D:4D ratio tend to show more prominent ADHD symptoms. Such findings support the hypothesis that the development of ADHD in children is affected by fetal testosterone exposure. ${ }^{12-14,22,23}$ However, some researches have not found a connection between the ratios of 2D:4D and ADHD symptoms in children. ${ }^{15}$ To sum up, it remains open for debate whether prenatal testosterone exposure plays an important role in the underlying cause of ADHD. In this context, we tried to replicate and expand the recent studies examining relationships between $2 \mathrm{D}: 4 \mathrm{D}$ ratios and ADHD by examining different effects on hyperactive-impulsive symptoms, inattentive, and aggression in a large, wellcharacterized, clinically evaluated ADHD sample. Also, to date, there is only one study examining the relation between the 2D: $4 \mathrm{D}$ ratios and intelligence quotient (IQ) in the ADHD sample. ${ }^{11}$ However, investigation of this relationship is worthwhile, as a recent review has stated that giftedness is related to higher levels of prenatal testosterone exposure. ${ }^{24}$

In the current study, we measured the ratios of 2D:4D and administered a Wechsler Intelligence Scale for Children-Revised (WISC-R) to assess IQ scores, as well as behavioral rat- ing scales, in children with ADHD and comparison individuals. The aim of the present study was to replicate and extend previous work by addressing two research questions: 1) Are 2D:4D ratios lower in ADHD than in controls? 2) Is there a correlation between 2D:4D ratios and symptoms of $\mathrm{ADHD}$, aggression and intelligence scores in boys with $\mathrm{ADHD}$ ?

\section{METHODS}

\section{Subjects}

Subjects were recruited from the child and adolescent psychiatry outpatient clinic of the Suleyman Demirel University Faculty of Medicine. The study was attended by a total of 155 children and adolescents between 7 and 16 years of age. The study included 100 treatment-naive male children diagnosed with ADHD and 55 healthy male children. The criteria for exclusion for the study were: 1) left-handedness, 2) the existence of a major neurological/physical disease (e.g., epilepsy, cerebral palsy, cardiovascular disorders, etc.), and major psychiatric disorder (e.g., schizophrenia, bipolar disorder, autism spectrum disorder) that can impair the cognitive and physical functions, 3) history of taking psychotropic medications, 4) an IQ scores below 70 according to the WISC-R, 5) Congenital or acquired malformation in the hands.

The SDU Faculty of Medicine Ethical Committee approved this study (2019/353) and all procedures were compliant with the Helsinki Declaration and local laws and regulations. After researchers clarified the aim and course of the research, the parents gave their written informed consent. Oral consent from all subjects was also received.

\section{Diagnostic and symptom assessment}

The Schedule for Affective Disorders and Schizophrenia for School-Aged Children, Present and Lifetime Version (KSADS-PL) was applied for patient and control subjects by a child psychiatrist (ÜI). ADHD diagnosis was made on the basis of the DSM-5 criteria.

To assess the children's ADHD and disruptive behavior symptoms severity, parents of the participants completed the Turgay DSM-IV-Based Child and Adolescent Behavioral Disorders Screening and Rating Scale (T-DSM-IV-S) ${ }^{25,26}$ and the Conners' Parent Rating Scale-Revised Short (CPRS-RS), ${ }^{27}$ and teachers of the participants completed the T-DSM-IV-S and the Conners' Teacher Rating Scale-Revised Short (CTRS-RS) ${ }^{28}$ To determine the children's aggression severity, participants filled out the Reactive-Proactive Aggression Questionnaire (RPAQ) ${ }^{29}$ Higher scores demonstrate higher levels of symptoms for each scale. The WISC- $\mathrm{R}^{30}$ was administered by licensed psychologists to participants for IQ determination. 


\section{Assessments of digit ratio and height and weight}

Previous studies have obtained finger length measurements indirectly from photocopies or hand scans. Since these measurements may distort ratios, ${ }^{31}$ the $2 \mathrm{D}$ and $4 \mathrm{D}$ finger lengths of both hands were measured with a digital vernier caliper directly by the same staff (UI). Participants were instructed to put their hands on the table with their palms facing up and to extend their fingers as much as possible. The procedure employed was the widely used measurement whereby absolute lengths of the digits of two hands are taken from the middle of the basal crease where the fingers join the palm to the tip of the fingers. The digit ratio was determined by dividing the $2 \mathrm{D}$ length by that of the $4 \mathrm{D}$. None of the participants in our study had a past medical history of a broken finger.

\section{Statistical analysis}

The normal distribution of the data was tested with the Kolmogorov-Smirnov test. The variables which were not normally distributed were compared with the Mann-Whitney U test. The student $t$-test was used to analyze the variables that were normally distributed. Variables are given as a number (n) and mean \pm standard deviation (SD). Correlations among continuous variables were examined by the Spearman rank correlation coefficient.

Multivariate analysis of covariance (MANCOVA) was conducted for potential confounding variables. This examined the main effect of a group that used the 2D:4D ratio of the right and left hand as outcome measures to control potential confounders (age and BMI percentiles), which were described as those variables linked to the outcome with a p-value less than 0.05 . We then conducted a one-way analysis of covariance (ANCOVA) to identify domains with significant between-group differences controlling for the same confounders. A value of $p$ less than 0.05 (two-tailed) was considered to indicate significance. The data were analyzed with the Statistical Package for the Social Sciences (SPSS), version 20 (IBM Corp., Armonk, NY, USA).

\section{RESULTS}

Descriptive statistics are presented in Table 1. There was no statistical difference between children with ADHD and control groups in terms of age differences between mother and child, father and child, and father and mother. Also, there was no significant difference between ADHD and control groups' breastfeeding duration. As presented in Table 1, there were significant differences for age, father's age, mother's age, and BMI Percentile, and verbal, performance and total intelligence scores based on the WISC-R.

The clinical characteristics of the ADHD sample and con-
Table 1. Demographic features of children with ADHD and control subjects

\begin{tabular}{lcccc}
\hline & $\begin{array}{c}\text { ADHD } \\
(\mathrm{N}=100)\end{array}$ & $\begin{array}{c}\text { Controls } \\
(\mathrm{N}=55)\end{array}$ & t or z & $\mathrm{p}$ \\
\hline Age, years & $9.7 \pm 2.3$ & $12 \pm 3$ & $-4.546^{\ddagger}$ & $<0.001^{*}$ \\
Mother's age, years & $34.4 \pm 5.9$ & $37.3 \pm 6.3$ & $-2.406^{\ddagger}$ & $0.016^{*}$ \\
Father's age, years & $38.2 \pm 5.7$ & $41.6 \pm 5.8$ & $-3.175^{\ddagger}$ & $<0.001^{*}$ \\
Age difference & & & & \\
$\quad$ Mother and child & $24.7 \pm 5.5$ & $25.3 \pm 4.7$ & $-0.672^{\dagger}$ & 0.503 \\
Father and child & $28.5 \pm 5.5$ & $29.6 \pm 4.7$ & $-1.281^{\dagger}$ & 0.202 \\
$\quad$ Father and mother & $3.7 \pm 3.2$ & $4.5 \pm 2.7$ & $-1.367^{\dagger}$ & 0.174 \\
Breastfeeding time & $13.8 \pm 8.2$ & $13.7 \pm 7.5$ & $0.082^{\dagger}$ & 0.935 \\
Weight percentile & $54.6 \pm 29.5$ & $66.1 \pm 28.5$ & $-2.469^{\ddagger}$ & $0.014^{*}$ \\
Height percentile & $51.6 \pm 30.1$ & $64.9 \pm 26.7$ & $-2.680^{\ddagger}$ & $0.007^{*}$ \\
BMI percentile & $53.8 \pm 29.9$ & $64.6 \pm 29.9$ & $-2.108^{\dagger}$ & $0.037^{*}$ \\
WISC-R & & & & \\
Verbal & $94.2 \pm 14$ & $107.2 \pm 12.4$ & $-4.426^{\ddagger}$ & $<0.001^{*}$ \\
Performance & $101.9 \pm 14.9$ & $108 \pm 16.5$ & $-2.039^{\dagger}$ & $0.044^{*}$ \\
Total & $97.8 \pm 13.8$ & $108.4 \pm 14.3$ & $-3.610^{\ddagger}$ & $<0.001^{*}$ \\
\hline Data & & & &
\end{tabular}

Data presented as mean \pm SD. ${ }^{*} \mathrm{p}<0.05$ (significance), tindependent t-test, $¥$ Mann-Whitney U-test. ADHD: attention-deficit/hyperactivity disorder, BMI: body mass index, WISC-R: Wechsler Intelligence Scale for Children-Revised

trols are presented in Table 2. The ADHD group's parent TDSM-IV-S, CPRS-RS, teacher T-DSM-IV-S, CTRS-RS, and RPAQ scores were higher than the controls.

The means and SD for 2D:4D ratios are shown in Table 3. We observed lower 2D:4D ratios in the right hand in ADHD in comparison to the control group as shown in Table 3 ( $\mathrm{p}=$ 0.004). The left-hand ratios of $2 \mathrm{D}: 4 \mathrm{D}$, however, did not differ between $\mathrm{ADHD}$ and control groups $(\mathrm{p}=0.161)$. There were significant overall group differences with respect to the digit ratio in MANCOVA [V (Pillais trace) $=0.045, \mathrm{~F}(2,148)=3.479$, $\left.\mathrm{p}=0.033, \eta_{\mathrm{p}}{ }^{2}=0.045\right]$. Separate univariate ANCOVAs on the outcome variables demonstrated significantly lower right hand 2D:4D ratios $\left[\mathrm{F}(1,149)=6.997, \mathrm{p}=0.009, \eta_{\mathrm{p}}{ }^{2}=0.045\right]$ in the ADHD group compared to the controls. However, in terms of the left-hand 2D:4D ratios, no significant differences were observed between groups $\left[\mathrm{F}(1,149)=0.573, \mathrm{p}=0.450, \mathrm{\eta}_{\mathrm{p}}{ }^{2}=0.004\right]$ (Table 3).

Correlations among 2D:4D ratios and age, BMI percentiles, verbal, performance, and total IQ scores, and subscale scores of the parent- and teacher-rated T-DSM-IV-S, CPRS-RS, CTRS$\mathrm{RS}$, and RPAQ were examined in the ADHD group (Table 4). There were negative correlations between the left-hand 2D: $4 \mathrm{D}$ ratios and the teacher-rated T-DSM-IV-S hyperactivityimpulsivity scores $(\mathrm{r}=-0.275, \mathrm{p}=0.020)$, and the CTRS-RS hyperactivity scores $(r=-0.262, p=0.041)$. However, no significant correlation was detected between right-hand 2D:4D ratios 
and the other psychological questionnaire scores. Also, there was no correlation between 2D:4D ratios of both hands and age, verbal, performance and total IQ scores, WISC-R subtests (information, similarities, arithmetic, comprehension, digit span, picture completion, picture arrangement, block design, object assembly, coding), and BMI percentiles.

Table 2. Clinical features of children with ADHD and control subjects

\begin{tabular}{|c|c|c|c|c|}
\hline & $\begin{array}{l}\text { ADHD } \\
(\mathrm{N}=100)\end{array}$ & $\begin{array}{c}\text { Controls } \\
(\mathrm{N}=55)\end{array}$ & $\mathrm{z}$ & $\mathrm{p}$ \\
\hline \multicolumn{5}{|c|}{ Parent T-DSM-IV-S } \\
\hline $\mathrm{AD}$ & $14.7 \pm 5.3$ & $4.2 \pm 3.4$ & -9.322 & $<0.001$ \\
\hline $\mathrm{HA} / \mathrm{I}$ & $16.2 \pm 6$ & $3.4 \pm 2.7$ & -9.458 & $<0.001$ \\
\hline OD & $11 \pm 4.9$ & $4 \pm 3.2$ & -7.785 & $<0.001$ \\
\hline $\mathrm{CD}$ & $3.6 \pm 3.7$ & $0.5 \pm 1$ & -6.818 & $<0.001$ \\
\hline \multicolumn{5}{|l|}{ CPRS-RS } \\
\hline OD & $9.5 \pm 4.3$ & $4 \pm 3.5$ & -6.636 & $<0.001$ \\
\hline CP-I & $11.8 \pm 4.2$ & $2.5 \pm 2.8$ & -9.080 & $<0.001$ \\
\hline HA & $9.8 \pm 4.4$ & $1.4 \pm 1.9$ & -8.901 & $<0.001$ \\
\hline \multicolumn{5}{|c|}{ Teacher T-DSM-IV-S } \\
\hline $\mathrm{AD}$ & $15.7 \pm 5.3$ & $3.4 \pm 4$ & -8.403 & $<0.001$ \\
\hline $\mathrm{HA} / \mathrm{I}$ & $13.5 \pm 7.2$ & $1.8 \pm 2.9$ & -8.053 & $<0.001$ \\
\hline OD & $9.1 \pm 5.7$ & $1.3 \pm 1.9$ & -7.870 & $<0.001$ \\
\hline $\mathrm{CD}$ & $3.8 \pm 5.1$ & $0.2 \pm 0.7$ & -6.581 & $<0.001$ \\
\hline \multicolumn{5}{|l|}{ CTRS-RS } \\
\hline OD & $4.6 \pm 3.9$ & $1 \pm 2.2$ & -5.337 & $<0.001$ \\
\hline CP-I & $6.9 \pm 3.6$ & $1 \pm 1.4$ & -7.658 & $<0.001$ \\
\hline HA & $10.5 \pm 5.7$ & $1 \pm 1.4$ & -8.014 & $<0.001$ \\
\hline \multicolumn{5}{|l|}{ RPAQ } \\
\hline Reactive & $10.1 \pm 4.7$ & $6 \pm 3.8$ & -4.713 & $<0.001$ \\
\hline Proactive & $3.4 \pm 3.5$ & $0.9 \pm 1.2$ & -5.008 & $<0.001$ \\
\hline Total & $13.5 \pm 7.7$ & $7 \pm 4.7$ & -5.159 & $<0.001$ \\
\hline
\end{tabular}

Mann-Whitney U-test. Data presented as mean \pm SD. ADHD: attention-deficit/hyperactivity disorder, T-DSM-IV-S: Turgay DSM IV-Based Child and Adolescent Behavioral Disorders Screening and Rating Scale, AD: attention-deficit, HA/I: hyperactivity-impulsivity, OD: oppositional defiant behavior, CD: conduct disorder, CTRS-RS: Conners Teacher Rating Scale-Revised Short, CPRSRS: Conners Parent Rating Scale-Revised Short, CP-I: cognitive problems-inattention, HA: hyperactivity, RPAQ: Reactive-Proactive Aggression Questionnaire

\section{DISCUSSION}

The present study has evaluated the ratios of $2 \mathrm{D}: 4 \mathrm{D}$ as an indicator of fetal testosterone exposure in male children with ADHD. Relationships between 2D:4D ratios and IQ, the severity of $\mathrm{ADHD}$ and disruptive behavior symptoms, and aggression were also explored. The analyses demonstrated that the right-hand 2D:4D ratios were significantly lower in $\mathrm{ADHD}$ patients compared to the control group. A significant negative correlation between hyperactivity and left-hand 2D:4D ratios were also observed. However, we could not find any correlation between the 2D:4D ratios and aggression levels and IQ scores in male children with ADHD.

Our findings showed lower right-hand 2D:4D ratios in male children with ADHD than in controls. Numerous researchers have investigated the 2D:4D ratios in ADHD in recent years and the majority have identified lower $2 \mathrm{D}: 4 \mathrm{D}$ ratios in ADHD. ${ }^{12-14,22,23}$ On the other hand, one study has also demonstrated that ADHD patients' 2D:4D ratios were not different from healthy controls. ${ }^{15}$ The results for the right and the lefthand ratios differ. In our current study, the right-hand 2D:4D ratio was found to be lower in ADHD patients than the controls, and the left-hand 2D:4D ratio did not differ between the groups. From previous research, it is understood that the findings for the left and the right-hand ratios are not exactly the same. ${ }^{18,32}$ A meta-analysis reported that the $2 \mathrm{D}: 4 \mathrm{D}$ ratio on the right hand might be a better indicator of fetal testosterone exposure than the $2 \mathrm{D}: 4 \mathrm{D}$ ratio on the left-hand, ${ }^{33}$ which may explain why in our study only the right-hand 2D:4D ratios were independently linked with ADHD. Taken together, we suggest that a significant statistical indicator of ADHD in male children is a low right-hand $2 \mathrm{D}: 4 \mathrm{D}$ ratios that may represent the level of fetal testosterone exposure. More research is required to understand how exposure to fetal testosterone may relate to the function and structure of the brain, which may predispose children to ADHD.

Furthermore, we found that exposure to fetal testosterone, estimated with 2D:4D ratios, exhibited a significant negative correlation with the hyperactivity scores in the teacher-rated questionnaire (T-DSM-IV-S and CTRS-RS) in boys with ADHD. Several studies have investigated the correlation between 2D:4D ratios and ADHD symptom severity. ${ }^{11,13,15,19,21}$ Similar

Table 3. Mean 2D:4D ratios of children with $A D H D$ and control subjects

\begin{tabular}{|c|c|c|c|c|c|c|c|}
\hline \multirow{2}{*}{ 2D:4D ratio } & \multirow{2}{*}{$\operatorname{ADHD}(\mathrm{N}=100)$} & \multirow{2}{*}{ Controls $(\mathrm{N}=55)$} & \multicolumn{2}{|c|}{ Independent t-test } & \multicolumn{3}{|c|}{ ANCOVA* } \\
\hline & & & $\mathrm{t}$ & $\mathrm{p}$ & $\mathrm{F}$ & $\mathrm{p}$ & $\eta_{\mathrm{p}}^{2}$ \\
\hline Right hand & $0.95 \pm 0.03$ & $0.96 \pm 0.03$ & -2.925 & 0.004 & 6.997 & 0.009 & 0.045 \\
\hline Left hand & $0.97 \pm 0.04$ & $0.98 \pm 0.03$ & -1.409 & 0.161 & 0.573 & 0.450 & 0.004 \\
\hline
\end{tabular}

*analysis of covariance (ANCOVA) was used after adjusted for age and BMI percentile for comparisons between two groups. ADHD: attention-deficit/hyperactivity disorder, BMI: body mass index 
Table 4. Correlations among 2D:4D ratios and demographic and psychiatric variables in boys with attention deficit/hyperactivity disorder

\begin{tabular}{|c|c|c|c|c|}
\hline & \multicolumn{2}{|c|}{$\begin{array}{l}\text { Right hand } \\
\text { 2D:4D ratio }\end{array}$} & \multicolumn{2}{|c|}{$\begin{array}{l}\text { Left hand } \\
\text { 2D:4D ratio }\end{array}$} \\
\hline & $\mathrm{p}$ & $\mathrm{r}$ & $\mathrm{p}$ & $\mathrm{r}$ \\
\hline Left hand 2D:4D ratio & 0.001 & 0.336 & - & - \\
\hline Age, years & 0.086 & -0.198 & 0.373 & 0.104 \\
\hline BMI Percentile & 0.889 & -0.014 & 0.463 & -0.074 \\
\hline WISC-R verbal & 0.472 & -0.083 & 0.223 & 0.140 \\
\hline WISC-R performance & 0.653 & -0.052 & 0.588 & -0.063 \\
\hline WISC-R total & 0.452 & -0.087 & 0.797 & 0.030 \\
\hline WISC-R information & 0.993 & -0.001 & 0.098 & 0.191 \\
\hline WISC-R similarities & 0.668 & -0.050 & 0.125 & 0.177 \\
\hline WISC-R arithmetic & 0.086 & -0.198 & 0.373 & 0.104 \\
\hline WISC-R comprehension & 0.473 & -0.083 & 0.766 & 0.035 \\
\hline WISC-R digit span & 0.196 & 0.150 & 0.534 & 0.072 \\
\hline WISC-R picture completion & 0.310 & -0.118 & 0.474 & -0.083 \\
\hline WISC-R picture arrangement & 0.490 & -0.080 & 0.748 & 0.037 \\
\hline WISC-R block design & 0.707 & -0.044 & 0.798 & -0.030 \\
\hline WISC-R object assembly & 0.608 & -0.060 & 0.556 & -0.069 \\
\hline WISC-R coding & 0.742 & -0.038 & 0.467 & -0.085 \\
\hline Parent T-DSM-IV-S AD & 0.549 & -0.062 & 0.089 & -0.175 \\
\hline Parent T-DSM-IV-S HA/I & 0.491 & 0.072 & 0.111 & -0.165 \\
\hline Parent T-DSM-IV-S OD & 0.316 & 0.104 & 0.688 & -0.042 \\
\hline Parent T-DSM-IV-S CD & 0.194 & 0.135 & 0.745 & 0.034 \\
\hline CPRS-RS OD & 0.720 & 0.037 & 0.955 & 0.006 \\
\hline CPRS-RS CP-I & 0.697 & 0.041 & 0.231 & -0.125 \\
\hline CPRS-RS HA & 0.585 & 0.057 & 0.178 & -0.140 \\
\hline Teacher T-DSM-IV-S AD & 0.338 & 0.115 & 0.563 & -0.070 \\
\hline Teacher T-DSM-IV-S HA/I & 0.130 & -0.181 & 0.020 & -0.275 \\
\hline Teacher T-DSM-IV-S OD & 0.401 & -0.102 & 0.398 & -0.103 \\
\hline Teacher T-DSM-IV-S CD & 0.511 & -0.080 & 0.202 & -0.154 \\
\hline CTRS-RS OD & 0.981 & 0.003 & 0.365 & 0.118 \\
\hline CTRS-RS CP-I & 0.451 & -0.079 & 0.103 & -0.169 \\
\hline CTRS-RS HA & 0.074 & -0.230 & 0.041 & -0.262 \\
\hline RPAQ reactive & 0.402 & 0.090 & 0.099 & 0.176 \\
\hline RPAQ proactive & 0.354 & 0.099 & 0.350 & 0.100 \\
\hline RPAQ total & 0.370 & 0.096 & 0.158 & 0.151 \\
\hline
\end{tabular}

WISC-R: Wechsler Intelligence Scale for Children-Revised, BMI: Body Mass Index, T-DSM-IV-S: Turgay DSM IV-Based Child and Adolescent Behavioral Disorders Screening and Rating Scale, AD: attention-deficit, HA/I: hyperactivity-impulsivity, OD: oppositional defiant behavior, CD: conduct disorder, CTRS-RS: Conners Teacher Rating Scale-Revised Short, CPRS-RS: Conners Parent Rating Scale-Revised Short, CP-I: cognitive problems-inattention, HA: hyperactivity, RPAQ: Reactive-Proactive Aggression Questionnaire to the results of our study, some studies showed a correlation between the 2D:4D ratios and hyperactive/impulsive symptoms. Williams et al., ${ }^{19}$ explored right-hand 2D:4D ratios associations with childhood problem behaviors and showed that lower 2D:4D ratios were associated with increased hyperactivity levels in girls, but not boys. In a sample of Caucasian boys and girls from the United Kingdom and Austria, Fink et al., ${ }^{21}$ examined the correlation between 2D:4D ratios and child disruptive behavior. In the United Kingdom sample, conduct problems and hyperactivity-inattention were associated with lower ratios of 2D:4D in boys, but not in girls. The lower 2D:4D ratios in the Austrian sample were correlated with more social issues in boys and more externalizing issues in girls. ${ }^{21}$ In another study, Martel et al., ${ }^{13}$ demonstrated that lower 2D: $4 \mathrm{D}$ ratios associated with a composite of teacher- and parentrated hyperactive-impulsive and inattentive symptoms in males. Roberts and Martel ${ }^{10}$ also showed that lower right-hand 2D:4D ratios were positively correlated with hyperactive-impulsive symptoms. Contrary to these studies, some studies did not detect any correlation between 2D:4D ratios and ADHD symptom severity. ${ }^{15}$ Lemiere et al., ${ }^{15}$ showed that the ratios of 2D:4D were statistically unrelated to any of the behavior assessment scales in the total group or the ADHD group. In recent study conduct by Wang et al., ${ }^{11}$ also showed that the ratios of 2D:4D were not correlated with behavioral symptoms among the boys with ADHD. In our study, only the left-hand ratios of 2D:4D were found to be correlated with the hyperactivity subscales of the teacher-rated scales. Although our study is similar to the results of other studies, there is not enough data about why this relationship is only in the left hand. To clarify this correlation, further studies are required.

In this study, no correlation was observed between the 2D:4D ratios and aggression in boys with ADHD. To our knowledge, there is only one study examining the relationship between 2D:4D ratios and aggression in patients with ADHD. In that study, the authors showed a relation between low 2D:4D ratios and increased aggression in patients with ADHD. ${ }^{14}$ However, several studies have examined the relation between the ratios of 2D:4D and aggression regardless of psychiatric diagnosis. Similar to the results of our study, several studies did not detect any relation between 2D:4D ratios and aggression. ${ }^{34-36}$ On the other hand, studies are reporting an association between low 2D:4D ratios and increased aggression. ${ }^{37-40}$ Systematic reviews and meta-analyses have been less equivocal in that, depending on the outcome under investigation (e.g., general aggression, sensation seeking/impulsivity), the effects of the 2D:4D ratios tend to be rather weak in overall magnitude. $^{33,41,42}$ The most recent criminological literature meta-analysis on the 2D:4D digit ratio has reached the same conclusion. ${ }^{43}$ The relation between 2D:4D ratios and aggression may not be 
simple, but maybe context-specific. Millet and Dewitte ${ }^{40}$ proposed possible negative correlations between the ratios of $2 \mathrm{D}$ : $4 \mathrm{D}$ and physical aggression during violent music video viewing, whereas no such association was observed after exposure to a nonviolent video. Also, Huh argued that people with low 2D:4D ratios prefer aggressive media. ${ }^{44} 2 \mathrm{D}: 4 \mathrm{D}$ ratios may, therefore, be a marker for recognizing the reason for people's preferences for media violence. Several prior reports into the relationship between 2D:4D ratios and aggression have focused on adults. Future studies might look at the relationship between aggression and 2D:4D ratios in ADHD children, especially for media violence.

Fetal gonadal hormones were also involved as significant factors in the development of different cognitive abilities such as memory, spatial skills, numerical, and verbal intelligence. ${ }^{45}$ Mrazik and Dombrowski ${ }^{24}$ contend that fetal testosterone exposure may be an etiological factor in giftedness. However, only a small number of studies investigate the relation between the ratios of 2D:4D and intelligence. ${ }^{11,46}$ Because of the complex nature of the observed association between $2 \mathrm{D}: 4 \mathrm{D}$ ratios and intelligence, Luxen and Buunk ${ }^{46}$ found evidence of an association between the ratios of 2D:4D and intelligence and detected a positive correlation between verbal intelligence and righthand 2D:4D ratios, a negative correlation between numerical intelligence and right-hand 2D:4D ratios. Brosnan ${ }^{47}$ demonstrated that 2D:4D ratios were positively correlated with literacy for females and negatively correlated with numeracy for males at age seven. Beaton et $\mathrm{al}^{48}$ detected no statistically significant associations between $2 \mathrm{D}: 4 \mathrm{D}$ ratios and mental rotation tasks. Nye et al. ${ }^{49}$ investigated the association between $2 \mathrm{D}$ : $4 \mathrm{D}$ ratios and academic performance and showed a relationship between the ratios of 2D:4D and student academic performance. In another study, Selvaraj et al., ${ }^{50}$ compared the ratios of 2D:4D of normal scorers and low scorers in cognition tests and the authors did not find any statistically significant difference in the cognition test domain. In a study with gifted children, Durdiaková et al. ${ }^{51}$ found lower 2D:4D ratios and salivary testosterone levels in the group of gifted boys compared to control boys. To our knowledge, there is only one study examining the relationship between intelligence and 2D:4D ratios in patients with ADHD. ${ }^{11}$ In this study, Wang et al., ${ }^{11}$ demonstrated no statistically significant correlations between 2D: $4 \mathrm{D}$ ratios and WISC-IV Chinese version. In our study, no correlation was found between WISC-R intelligence test verbal, performance, and total score, and subtest scores and the ratios of 2D:4D in ADHD. The lack of significant correlations in the present study could be attributed to the difference in methodology. Further studies are needed to explain the relationship between intelligence level and fetal testosterone exposure in patients with ADHD.
The empirical results reported herein should be considered in light of some strengths and limitations. Accounting for the age and BMI percentile, including only treatment-naïve patients and the evaluation of ADHD symptoms by both teacher and parent, is a strong point of the present study. Nevertheless, there are several limitations to the present study. First, since our sample consists of only male patients with ADHD, we cannot expand our findings to all ADHD patients. Second, we measured only 2D:4D ratios as a marker of fetal testosterone. There are more valid and reliable invasive methods for fetal testosterone measurement. Finally, we did not conduct multiple finger length measurements; thus, we did not conduct intra-class comparisons.

In conclusion, we found a lower right-hand $2 \mathrm{D}: 4 \mathrm{D}$ ratios as an indicator of fetal testosterone exposure in treatment-naive children with ADHD compared with healthy controls. Also, a significant negative correlation was noted between hyperactivity scores and left-hand 2D:4D ratios. These results provide further evidence that fetal androgen exposure may contribute to the pathophysiology of ADHD.

\section{Conflicts of Interest}

The authors have no potential conflicts of interest to disclose.

\section{Author Contributions}

Conceptualization: Ümit Işık, Faruk Kılıç, Bilal Tanrıtanır. Data curation: Ümit Işık, Faruk Kılıç, Evrim Aktepe. Formal analysis: Ümit Işık, Faruk Kılıç, Bilal Tanritanır. Funding acquisition: all authors. Investigation: all authors. Methodology: all authors. Project administration: Ümit Işık. Resources: all authors. Software: all authors. Supervision: Ümit Ișı. Validation: all authors. Visualization: all authors. Writing_original draft: Ümit Işık. Writing-review \& editing: all authors.

\section{ORCID iDs}

Ümit Işık

Faruk Kılıç

Evrim Aktepe

Bilal Tanritanır

https://orcid.org/0000-0001-6006-3247

https://orcid.org/0000-0002-2259-4028

https://orcid.org/0000-0002-3082-4428

https://orcid.org/0000-0002-6538-3511

\section{REFERENCES}

1. Ercan ES, Polanczyk G, Akyol Ardıc U, Yuce D, Karacetın G, Tufan AE, et al. The prevalence of childhood psychopathology in Turkey: a crosssectional multicenter nationwide study (EPICPAT-T). Nord J Psychiatry 2019;73:132-140.

2. Ramtekkar UP, Reiersen AM, Todorov AA, Todd RD. Sex and age differences in attention-deficit/hyperactivity disorder symptoms and diagnoses: implications for DSM-V and ICD-11. J Am Acad Child Adolesc Psychiatry 2010;49:217-228.e1-3.

3. Willcutt EG. The prevalence of DSM-IV attention-deficit/hyperactivity disorder: a meta-analytic review. Neurotherapeutics 2012;9:490-499.

4. Scassellati C, Bonvicini C, Faraone SV, Gennarelli M. Biomarkers and attention-deficit/hyperactivity disorder: a systematic review and metaanalyses. J Am Acad Child Adolesc Psychiatry 2012;51:1003-1019.e20.

5. Faraone SV, Asherson P, Banaschewski T, Biederman J, Buitelaar JK, Ramos-Quiroga JA, et al. Attention-deficit/hyperactivity disorder. Nat Rev Dis Prim 2015;1:15020.

6. Sharma A, Couture J. A review of the pathophysiology, etiology, and treatment of attention-deficit hyperactivity disorder (ADHD). Ann 
Pharmacother 2014;48:209-225.

7. Davies W. Sex differences in attention deficit hyperactivity disorder: candidate genetic and endocrine mechanisms. Front Neuroendocrinol 2014;35:331-346.

8. Golubchik P, Lewis M, Maayan R, Sever J, Strous R, Weizman A. Neurosteroids in child and adolescent psychopathology. Eur Neuropsychopharmacol 2007; 17:157-164.

9. Işık Ü, Bilgiç A, Toker A, Kılınç I. Serum levels of cortisol, dehydroepiandrosterone, and oxytocin in children with attention-deficit/hyperactivity disorder combined presentation with and without comorbid conduct disorder. Psychiatry Res 2018;261:212-219.

10. Roberts BA, Martel MM. Prenatal testosterone and preschool disruptive behavior disorders. Pers Individ Dif 2013;55:962-966.

11. Wang LJ, Chou MC, Chou WJ, Lee MJ, Lee SY, Lin PY, et al. Potential role of pre- and postnatal testosterone levels in attention-deficit/hyperactivity disorder: is there a sex difference? Neuropsychiatr Dis Treat 2017; 13:1331-1319.

12. Martel M. Conscientiousness as a mediator of the association between masculinized finger-length ratios and attention-deficit/hyperactivity disorder (ADHD). J Child Psychol Psychiatry 2009;50:790-798.

13. Martel M, Gobrogge K, Breedlove M, Nigg J. Masculinized finger-length ratios of boys, but not girls, are associated with attention-deficit/hyperactivity disorder. Behav Neurosci 2008;122:273-281.

14. Demirci EÖ, Öztop DB. Dikkat eksikliği ve hiperaktivite bozukluğu olan erkek çocuk ve ergenlerde agresyon, empati ve 2D:4D parmak oranlarının ilişkisi. Yeni Symp 2015;53:2-8.

15. Lemiere J, Boets B, Danckaerts M. No association between the 2D:4D fetal testosterone marker and multidimensional attentional abilities in children with ADHD. Dev Med Child Neurol 2010;52:e202-e208.

16. Brown WM, Hines M, Fane BA, Breedlove SM. Masculinized finger length patterns in human males and females with congenital adrenal hyperplasia. Horm Behav 2002;42:380-386.

17. Manning JT, Bundred PE, Flanagan BF. The ratio of 2 nd to 4 th digit length: a proxy for transactivation activity of the androgen receptor gene? Med Hypotheses 2002;59:334-336.

18. Manning JT, Scutt D, Wilson J, Lewis-Jones DI. The ratio of 2 nd to 4 th digit length: a predictor of sperm numbers and concentrations of testosterone, luteinizing hormone and oestrogen. Hum Reprod 1998;13: 3000-3004.

19. Williams JHG, Greenhalgh KD, Manning JT. Second to fourth finger ratio and possible precursors of developmental psychopathology in preschool children. Early Hum Dev 2003;72:57-65.

20. Stevenson JC, Everson PM, Williams DC, Hipskind G, Grimes M, Mahoney ER. Attention deficit/hyperactivity disorder (ADHD) symptoms and digit ratios in a college sample. Am J Hum Biol 2007;19:41-50.

21. Fink B, Manning JT, Williams JHG, Podmore-Nappin C. The 2 nd to 4 th digit ratio and developmental psychopathology in school-aged children. Pers Individ Dif 2007;42:369-379.

22. de Bruin EI, Verheij F, Wiegman T, Ferdinand RF. Differences in finger length ratio between males with autism, pervasive developmental disorder-not otherwise specified, ADHD, and anxiety disorders. Dev Med Child Neurol 2006;48:962-965.

23. McFadden D, Westhafer JG, Pasanen EG, Carlson CL, Tucker DM. Physiological evidence of hypermasculinization in boys with the inattentive type of attention-deficit/hyperactivity disorder (ADHD). Clin Neurosci Res 2005;5:233-245.

24. Mrazik M, Dombrowski SC. The neurobiological foundations of giftedness. Roeper Rev 2010;32:224-234.

25. Turgay A. Disruptive Behavior Disorders Child and Adolescent Screening and Rating Scales for Children, Adolescents, Parents and Teachers. West Bloomfield, MI: Michigan Integrative Therapy Institute Publication; 1994.

26. Ercan ES, Amado S, Somer O, Çıkoğlu S. Development of a test battery for the assessment of attention deficit hyperactivity disorder [in Turkish]. J Child Adolesc Ment Health 2001;8:132-144.

27. Kaner S, Büyüköztürk Ş, İşeri E. Conners parent rating scale-revised short: Turkish standardization study. Eğitim ve Bilim 2013;38:81-97.

28. Kaner S, Büyüköztürk Ş, İşeri E. Conners teacher rating scale-revised short: Turkish adaptation study. Educ Sci 2013;38:81-97.

29. Baş AU, Yurdabakan I. Factor structure of the reactive-proactive aggression questionnaire in Turkish children and gender, grade-level, and socioeconomic status differences in reactive and proactive aggression. J Psychoeduc Assess 2012;30:284-297.

30. Savaşır I, Şahin N. Manual for the Wechsler Intelligence Scale for Children-Revised (WISC-R). Ankara: Turkish Pscyhology Association Publication; 1995.

31. Manning JT, Fink B, Neave N, Caswell N. Photocopies yield lower digit ratios (2D:4D) than direct finger measurements. Arch Sex Behav 2005; 34:329-333.

32. Kilic F, Isik U, Demirdas A, Ayaz F. Investigation of second to fourth finger length ratio (2D:4D) in schizophrenia patients. Dusunen Adam J Psychiatry Neurol Sci 2019;32:295-301.

33. Hönekopp J, Watson S. Meta-analysis of the relationship between digitratio 2D:4D and aggression. Pers Individ Dif 2011;51:381-386.

34. Cicek IE, Cicek E, Demirel B, Ayhan MG, Varsak N, Özbek SY, et al. Digit ratio (2D:4D), impulsiveness and aggression in male heroin addicts: a prospective controlled study. Pers Individ Dif 2017;117:1-5.

35. Golby J, Meggs J. Exploring the organizational effect of prenatal testosterone upon the sporting brain. J Sport Sci Med 2011;10:445-451.

36. Hurd PL, Vaillancourt KL, Dinsdale NL. Aggression, digit ratio and variation in androgen receptor and monoamine oxidase A genes in men. Behav Genet 2011;41:543-556.

37. Bailey AA, Hurd PL. Finger length ratio (2D:4D) correlates with physical aggression in men but not in women. Biol Psychol 2005;68:215-222.

38. Benderlioglu Z, Nelson RJ. Digit length ratios predict reactive aggression in women, but not in men. Horm Behav 2004;46:558-564.

39. Coyne SM, Manning JT, Ringer L, Bailey L. Directional asymmetry (right-left differences) in digit ratio (2D:4D) predict indirect aggression in women. Pers Individ Dif 2007;43:865-872.

40. Millet K, Dewitte S. Digit ratio (2D:4D) moderates the impact of an aggressive music video on aggression. Pers Individ Dif 2007;43:289-294.

41. Voracek M, Tran US, Dressler SG. Digit ratio (2D:4D) and sensation seeking: new data and meta-analysis. Pers Individ Dif 2010;48:72-77.

42. Turanovic JJ, Pratt TC, Piquero AR. Exposure to fetal testosterone, aggression, and violent behavior: a meta-analysis of the 2D:4D digit ratio. Aggress Violent Behav 2017;33:51-61.

43. Pratt TC, Turanovic JJ, Cullen FT. Revisiting the criminological consequences of exposure to fetal tetosterone: a meta-analysis of the $2 \mathrm{D}: 4 \mathrm{D}$ digit ratio*. Criminology 2016;54:587-620.

44. Huh HR. Digit ratios and preferences for aggressive content in entertainment. Pers Individ Dif 2011;51:451-453.

45. Bull R, Davidson WA, Nordmann E. Prenatal testosterone, visual-spatial memory, and numerical skills in young children. Learn Individ Differ 2010;20:246-250.

46. Luxen MF, Buunk BP. Second-to-fourth digit ratio related to Verbal and Numerical Intelligence and the Big Five. Pers Individ Dif 2005;39: 959-966.

47. Brosnan MJ. Digit ratio as an indicator of numeracy relative to literacy in 7-year-old British schoolchildren. Br J Psychol 2008;99:75-85.

48. Beaton AA, Magowan SV, Rudling NG. Does handedness or digit ratio (2D:4D) predict lateralised cognitive ability? Pers Individ Dif 2012;52: 627-631.

49. Nye JVC, Bryukhanov M, Polyachenko S. 2D:4D and lifetime educational outcomes: Evidence from the Russian RLMS survey. Pers Individ Dif 2017;112:62-66.

50. Selvaraj R, Prathibha M, Devaraj V. 2D:4D ratio and its association with examination scores and cognitive abilities in adolescent students-a crosssectional study. Natl J Physiol Pharm Pharmacol 2017;8:62-67.

51. Durdiaková J, Lakatošová S, Kubranská A, Laznibatová J, Ficek A, Ostatníková $\mathrm{D}$, et al. Mental rotation in intellectually gifted boys is affected by the androgen receptor CAG repeat polymorphism. Neuropsychologia 2013;51:1693-1698. 